\title{
Analisis Kebutuhan Mahasiswa terhadap Penggunaan E-Modul pada Perkuliahan Fisika Matematika I Materi Vektor
}

\author{
Auliya Ramadhanti ${ }^{1)^{*}}$, Astalini ${ }^{1),}$, Darmaji ${ }^{1)}$ \\ ${ }^{1)}$ Pendidikan Fisika Fakultas Keguruan dan Ilmu Pendidikan, Universitas Jambi \\ *auliyadhanti@gmail.com
}

Abstrak: Tujuan dari penelitian ini ialah untuk mengetahui bagaimana level serta pendapat mahasiswa mengenai e-modul materi vektor yang akan dikembangkan. Jenis penelitian ini ialah mixed method dengan teknik pengambilan sampel yang digunakan ialah purposive sampling. Sampel yang digunakan merupakan mahasiswa aktif kelas reguler C 2019 yang pernah mengontrak mata kuliah fisika matematika I. Instrumen yang digunakan ialah berupa angket dan lembar wawancara yang dimana di analisis menggunakan statistik deskriptif. Hasil yang didapatkan menunjukkan bahwa sebagian besar sampel berpendapat bahwa e-modul merupakan gagasan yang sangat baik, hal ini dapat dilihat dari hasil statistik deskriptif nilai rata-rata sebesar 23,07 dimana berada pada kategori dibutuhkan, hasil data kuantitatif ini diperkuat dengan hasil wawancara yang sebagian besar mendukung pembuatan e-modul ini.. Penggunaan e-modul pada mata kuliah Fisika Matematika dapat membantu mahasiswa belajar secara mandiri. Penelitian ini dapat dijadikan sebagai referensi untuk penelitian e-modul Fisika Matematika ke depannya.

Kata Kunci: e-Module, Analisis Kebutuhan, dan Fisika Matematika I.

\section{PENDAHULUAN}

Pendidikan merupakan sesuatu yang tidak terlepas dan bersifat sangat penting dalam kehidupan manusia, karena melalui pendidikan akan terbentuk sumber daya manusia yang berkualitas (Kimbrel, 2020). Pendidikan yang dibangun di atas kompetensi abad ke-21 (era revolusi 4.0) berfokus pada pembelajaran yang mengharuskan siswa memiliki kemampuan keterampilan, pengetahuan, pemahaman konsep, dan kemampuan di bidang teknologi, media, dan informasi (Huda et al., 2019). Kualitas pendidikan dapat diraih dengan memanfaatkan teknlogi, salah satunya dalam penyelenggaraan pendidikan secara umum maupun sebagai media pembelajaran di kelas karena akan sangat membantu siswa (Nurabadi et al., 2018). Sehingga berdasarkan hal diatas media yang cocok dengan perkembangan zaman ialah dengan pengembangan bahan ajar elektronik.

Bahan ajar merupakan bahan, informasi, alat/media yang digunakan dosen untuk melaksanakan pembelajaran termasuk menciptakan suasana yang mendorong mahasiswa untuk belajar (Mahande, 2019). Emodul adalah salah satu produk bahan ajar non cetak berbasis digital yang dapat menampilkan teks, gambar, animasi, dan video melalui piranti elektronik berupa computer atau smartphone (Astalini et al., 2019). E-modul juga merupakan sumber belajar yang berisi materi, metode, batasan dan metode evaluasi yang sistematis dan menarik bagi siswa yang dirancang untuk mencapai kompetensi yang sesuai dengan kurikulum secara elektronik (Mazidah et al., 2020) Menurut penelitian dari Mulyadi et al., 2020 penggunaan e-modul dapat meningkatan efektivitas belajar siswa dalam memahami materi. Kemampuan siswa dalam memahami materi tentunya menjadi focus utama dalam pembuatan e-modul, salah satunya jika materi tersebut sulit dan bersifat abstrak seperti halnya ilmu fisika.

Fisika merupakan suatu cabang ilmu pengetahuan sains yang objek kajiannya terdiri atas kompleksitas hubungan antar fenomena yang pada akhirnya menjadi suatu konsep atau teori (Trianggono, 2017). Pemecahan masalah dalam fisika sangat penting dan terbilang sulit dan kurang diminati peserta didik (Riantoni et al., 2017). Fisika sendiri memiliki banyak cabang ilmu yang jika dipelajari lebih lanjut akan sangat bermanfaat bagi kehidupan manusia salah satunya ialah Fisika Matematika (Ayu et al., 2021). Fisika matematika ialah salah satu cabang kajian ilmu fisika yang membahas secara tersusun dan sistematis mengenai teori kuantum secara analitis 
dengan menggunakan persamaan-persamaan matematis (Petrova, 2020). Banyak mahasiswa mengalami kesulitan untuk mendapatkan hasil yang memuaskan dalam perkuliahan ini, kebanyakan dari mereka berpendapat media pembelajaran yang cukup sedikit dan juga masih berbahasa asing menjadi salah satu kendala dalam memahami materi (Darmaji, Astalini, \& Kurniawan, 2019). Salah satunya ialah materi vector, meskipun sudah pernah dipelajari pada perkuliahan Fisika Dasar, namun konsep vector dalam Fisika Matematika memegang peranan yang penting dikarenakan vector menjadi dasar serta menjadi syarat dalam mempelajari materi selanjutnya dalam perkuliahan Fisika Matematika. Selain itu materi vector sendiri akan berkesinambungan dengan mata kuliah lanjutan seperti Fisika Modern, Fisika Inti, dan lain sebagainya yang masih memanfaatkan pengaplikasian Fisika Matematika.

Penelitian yang relevan dengan penelitian ini adalah penelitian yang dilakukan oleh Ellianawati \& Wahyuni (2012) tentang pengembangan bahan ajar Fisika Matematika berbasis self regulated learning sebagai upaya peningkatan kemampuan belajar mandiri. Lalu penelitian yang dilakukan oleh Amilia, Andriani \& Zulherman (2016) dengan judul "Pengembangan Bahan Ajar Cetak Mata Kuliah Fisika Matematika Pokok Bahasan Bilangan Kompleks Di Program Studi Pendidikan Fisika Universitas Sriwijaya” dengan hasil penelitian menunjukkan bahwa bahan ajar yang dikembangkan sudah tergolong valid dan praktis, sehingga layak digunakan sebagai bahan ajar tambahan pada mata kuliah Fisika Matematika. Serta penelitian oleh Saputri, Fadilah \& Wahyudi (2016) tentang Efektivitas Penggunaan Buku Ajar Fisika Matematika Berbasis Inkuiri dalam Perkuliahan Fisika Matematika menunjukkan bahwa peningkatan kemampuan pemecahan masalah matematis mahasiswa pada perkuliahan Fisika Matematika tergolong baik, dan respon mahasiswa terhadap buku ajar tergolong baik maka penggunaan buku ajar Fisika Matematika berbasis inkuiri efektif dalam perkuliahan Fisika Matematika.

Berdasarkan hal tersebut penulis berpendapat bahwa salah satu solusi dalam mengatasi permasalahan tersebut ialah dengan membuat sebuah e-modul yang terintegrasi dengan materi vektor. Namun sebelum membuat sebuah e-modul, perlu untuk menganalisis bagaimana kebutuhan maupun pendapat mahasiswa mengenai e-modul yang nantinya akan dibuat. Berdasarkan penjabaran diatas, maka tujuan dari penelitian ini ialah; (1) mendeskripsikan tingkat kebutuhan siswa terhadap e-modul materi vektor mata kuliah fisika matematika I; (2) mendeskripsikan pendapat mahasiswa mengenai e-modul materi vektor mata kuliah fisika matematika I.

\section{METODE}

Jenis penelitian yang dipilih penulis ialah mixed method. Penelitian mixed method sendiri ialah penelitian yang menggabungkan data kuantitatif dan data kualitatif dalam penelitian. Penelitian kuantitatif digunakan untuk melakukan penelitian terhadap suatu populasi atau sampel tertentu, instrumen pengumpulan data, penelitian dan analisis atau statistik data (Darmaji, Kurniawan, Astalini, Kurniawan, et al., 2019). Penelitian kualitatif merupakan studi tentang sifat fenomena (Busetto, Wick \& Gumbinger, 2020). Sampel yang digunakan ialah mahasiswa aktif kelas C pendidikan fisika angkatan 2019 yang pernah mengontrak mata kuliah fisika matematika I. Teknik pengambilan sampel yang digunakan ialah purposive sampling, purposive sampling ialah sebuah teknik pengambilan sampel yang dilakukan dengan menentukan kategori dari sampelnya (Ahmad et al., 2020).

Instrumen yang digunakan dalam pengambilan data dibedakan menjadi dua yaitu instrumen kuantitatif berupa angket kebutuhan mahasiswa dan instrumen kualitatif berupa lembar wawancara. Angket kebutuhan yang digunakan berisi 6 pernyataan, untuk kisi-kisi instrumen angket kebutuhan dapat ditunjukkan pada tabel 1.

Tabel 1. Kisi-kisi instrumen angket kebutuhan mahasiswa

\begin{tabular}{cc}
\hline Indikator & No. pernyataan \\
\hline Kesulitan Materi & 1 \\
Kondisi media yang digunakan & $2,3,4,5,6$ \\
\hline
\end{tabular}

Angket di sebarkan kepada 30 mahasiswa yang memiliki skala likert 1 sampai 5 yang rinciannya: 1 (sangat tidak setuju), 2 (tidak setuju), 3 (Cukup setuju), 4 (setuju), 5 (sangat setuju). Kemudian untuk rentangnya ditentukan sebagai berikut. 
Tabel 2. Rentang kategori angket kebutuhan mahasiswa

\begin{tabular}{cc}
\hline Interval & Level kebutuhan mahasiswa \\
\hline $25,21-30,00$ & Sangat dibututuhkan \\
$20,05-25,20$ & Dibutuhkan \\
$15,61-20,04$ & Cukup dibutuhkan \\
$10,81-15,60$ & Tidak dibutuhkan \\
$6,00-10,80$ & Sangat tidak dibutuhkan \\
\hline
\end{tabular}

Lalu untuk wawancaranya berisi 12 pertanyaan yang diajukan kepada 10 mahasiswa terkait kebutuhan siswa mengenai media berupa e-modul dalam pembelajaran fisika matematika I materi vektor. Adapun untuk kisi-kisi lembar wawancaranya dapat dilihat pada tabel 3.

Tabel 3. Kisi-kisi instrumen wawancara mahasiswa

\begin{tabular}{cc}
\hline Indikator & No. Butir \\
\hline Mengikuti proses perkuliahan fisika matematika I & $1,2,3$ \\
Bahan ajar yang digunakan pada perkuliahan & 4,5 \\
Kendala atau masalah pada perkuliahan & 6,7 \\
Solusi yang diharapkan oleh peserta perkuliahan & 8 \\
Jika dibuatkan modul, modul seperti apa yang diharapkan oleh peserta perkuliahan & $9,10,11,12$ \\
\hline
\end{tabular}

Setelah data didapatkan, penulis selanjutnya melakukan penganalisisan data. Teknik analisis data yang digunakan ialah statistik deskriptif untuk data kuantitatif dan miles huberman untuk data wawancara dengan mahasiswa. Data kuantitatif yang dianalisis menggunakan statistik deskriptif seperti perhitungan mean, median, modus, dan lain-lain (Odhier, Odhier, Ajowi \& Mwebi, 2019). Data kualitatif yang diperoleh dianalisis dengan analisis miles \& Huberman.

\section{HASIL DAN PEMBAHASAN}

Untuk mempermudah pemahaman dan pembaca, maka hasil dan pembahasan langsung disatukan, sehingga setiap hasil yang didapat maka langsung dibahas sesuai dengan teori yang relevan. Hasil penelitian dalam pendekatan kuantitatif dapat disajikan dalam bentuk tabel angka-angka, grafik, deskripsi verbal atau gabungan ketiganya. Kemudian, hasil penelitian dalam bentuk pendekatan kualitatif yang bersumber dari wawancara, pengamatan, penafsiran isi teks, dan lain-lain dikondensasikan, disarikan, atau dibuat ke dalam ringkasan substansial. Jadi, yang disajikan adalah temuan-temuan substansial yang dapat disajikan dalam bentuk tabel-tabel deskriptif untuk memudahkan pemahaman oleh pembaca. Potongan wawancara, deskripsi hasil pengamatan, kutipan teks, dan lain-lain yang memuat temuan-temuan utama atau jawaban dari pertanyaan penelitian disajikan dalam pembahasan sebagai contoh otentik.

Hasil uji statistik deskriptif dibantu oleh aplikasi SPSS versi 22, adapun untuk hasilnya dapat dilihat pada tabel dibawah ini.

Tabel 4. Hasil uji statistik deskriptif level kebutuhan mahasiswa terhadap e-modul

\begin{tabular}{cccccccc}
\hline Interval & Level kebutuhan mahasiswa & $F$ & $\%$ & Mean & Median & Max & Min \\
\hline $25,21-30,00$ & Sangat dibututuhkan & 5 & 16,66 & & & & \\
$20,05-25,20$ & Dibutuhkan & 20 & 66,66 & & & & \\
$15,61-20,04$ & Cukup dibutuhkan & 5 & 16,66 & 23,07 & 23 & 28 & 19 \\
$10,81-15,60$ & Tidak dibutuhkan & 0 & 0 & & & & \\
$6,00-10,80$ & Sangat tidak dibutuhkan & 0 & 0 & & & & \\
\hline
\end{tabular}

Untuk memperkuat hasil data kuantitatif, peneliti juga mengumpulkan data kualitatif yaitu dengan melakukan wawancara. Adapun hasil wawancara dapat dilihat pada tabel 5.

Tabel 5 menunjukkan hasil wawancara dari beberapa narasumber yakni mahasiswa, hasil yang didapatkan kebanyakan positif dan mendukung pembuatan e-modul vektor mata kuliah fisika matematika.

Berdasarkan hasil uji statistik deskriptif pada tabel 4, didapatkan bahwa sebanyak 5 orang mahasiswa menganggap bahwa e-modul sangat dibutuhkan, 20 orang menganggap e-modul dibutuhkan, dan sisanya 5 orang 
menganggap e-modul cukup dibutuhkan dalam pembelajaran fisika matematika. Dengan mengacu pada hasil tersebut maka dapat dilihat bahwa sebagian besar mahasiswa membutuhkan sebuah media pembelajaran interaktif dalam membantu mereka dalam memahami materi vektor pada mata kuliah fisika matematika.

Tabel 5. Hasil wawancara kebutuhan mahasiswa terhadap e-modul

\begin{tabular}{lll}
\hline \multicolumn{1}{c}{ Pertanyaan } & \multicolumn{1}{c}{ Jawaban } \\
\hline $\begin{array}{l}\text { Apakah saudara sudah mengikuti perkuliahan fisika } \\
\text { matematika I? }\end{array}$ & Sudah \\
\hline $\begin{array}{l}\text { Apakah ini pertama kali saudara mengikuti } \\
\text { perkuliahan fisika matematika I? }\end{array}$ & Iya \\
\hline $\begin{array}{l}\text { Berapa kali saudara mengikuti perkuliahan fisika } \\
\text { matematika I? }\end{array}$ & Satu \\
\hline $\begin{array}{l}\text { Apakah saudara memiliki literatur pada perkuliahan } \\
\text { fisika matematika I? }\end{array}$ & Sebagian ada \\
\hline $\begin{array}{l}\text { Bagaimana menurut saudara tentang literasi yang } \\
\text { digunakan dalam perkuliahan fisika matematika I? }\end{array}$ & Cukup membantu namun sulit dipahami \\
\hline $\begin{array}{l}\text { Apakah saudara memiliki kendala atau masalah } \\
\text { selama perkuliahan fisika matematika I? }\end{array}$ & $\begin{array}{l}\text { Kendalanya ialah dalam pemahaman butuh waktu } \\
\text { bang lama dan bahan ajar yang ada menggunakan } \\
\text { Apakah salah satu kendala atau masalah perkuliahan }\end{array}$ & $\begin{array}{l}\text { Iya } \\
\text { terletak pada bahan ajar? }\end{array}$ \\
\hline $\begin{array}{l}\text { Apa yang saudara harapkan dari bahan ajar fisika } \\
\text { matematika I? }\end{array}$ & $\begin{array}{l}\text { Lebih mendetail lagi penjelasannya dan digunakan } \\
\text { bahasa yang mudah dipahami }\end{array}$ \\
\hline $\begin{array}{l}\text { Apakah saudara senang jika fisika matematika I ada } \\
\text { dalam bentuk modul elektronik? }\end{array}$ & Sangat senang karena dapat membantu perkuliahan \\
\hline $\begin{array}{l}\text { Bagaimana menurut saudara jika fisika matematika I } \\
\text { dibuatkan modul perkuliahan berbasis elektronik? }\end{array}$ & $\begin{array}{l}\text { Saya setuju, karena mempermudah mahasiswa } \\
\text { mengaksesnya tanpa harus terbebani dalam bentuk } \\
\text { cetakan }\end{array}$ \\
\hline $\begin{array}{l}\text { Jika ada modul elektronik fisika matematika I, apa } \\
\text { menurut saudara dapat membantu proses } \\
\text { perkuliahan fisika matematika I? }\end{array}$ & $\begin{array}{l}\text { Tentu saja, selama penyajian materinya jelas dan } \\
\text { relevan }\end{array}$ \\
\hline $\begin{array}{l}\text { Jika ada modul elektronik fisika matematika I, apa } \\
\text { yang saudara harapkan dari modul elektronik } \\
\text { tersebut? }\end{array}$ & $\begin{array}{l}\text { Diharapkan dapat disajikan dengan jelas, ringkas } \\
\text { naman detail dalam penyelesaian permasalahannya }\end{array}$ \\
\hline
\end{tabular}

Hasil uji statistik deskriptif diperkuat dengan hasil wawancara yang menyatakan hasil yang positif dimana mahasiswa mendukung pembuatan e-modul yang telah ditawarkan oleh peneliti. Hasil wawancara ini sendiri ditujukan untuk memperkuat data kuantitatif yang terlebih dahulu di dapatkan (Busetto et al., 2020). Dari hasil wawancara, dapat dilihat bahwa salah satu kendala yang menyebabkan mereka kurang memahami materi ialah sumber belajar yang berbahasa inggris, hal ini sendiri serupa ditemukan pada penelitian Astalini et al. (2021) yang berpendapat bahwa salah satu kendala utama yang memebuat mahasiswa menalami kesulitan dalam memahami materi Fisika Matematika ialah buku ajar utama yang digunakan masih berbahasa inggris. Berdasarkan hal tersebut, maka penulis menganggap bahwa e-modul perlu dikembangkan lebih lanjut.

Pada dasarnya dalam perkuliahan sendiri modul dapat dikatakan penting bagi mahasiswa, dengan adanya kemajuan teknologi informasi serta pola kehidupan mahasiswa yang telah banyak mengalami perubahan maka modul berupa elektronik memiliki potensi besar untuk digunakan dalam proses pembelajaran (Rendra et al., 2018). E-modul sendiri akan membantu dalam pengurangan penggunaan kertas untuk mencetak buku atau modul, ukuran file nya juga cenderung kecil sehingga dapat disimpan dalam flashdisk, pengajar maupun mahasiswa juga dapat mengakses e-modul tanpa dibatasi oleh ruang dan waktu, serta fleksibel karena didalamnya terdapat link yang akan memudahkan mahasiswa untuk menuju informasi tertentu (Puspitasari, 2019).

Penelitian ini pada dasarnya merupakan tahapan awal dalam mengembangkan suatu media pembelajaran. Penelitian ini sangat berguna terkhusus untuk penulis agar mengetahui karakteristik suatu populasi sampel. Selain itu, analisis awal berguna dalam memudahkan peneliti dalam menyusun perencanaan yang nantinya akan 
dilakukan dalam mengembangkan suatu media pembelajaran. Kemudian bagi mahasiswa, penelitian ini berguna untuk melihat seberapa pentingnya penggunaan media dalam pembelajaran khususnya Fisika, dengan begitu mahasiswa dapat menganalisis kesulitan mereka dalam memahami materi. Lalu bagi pengajar, penelitian ini berguna untuk mengetahui karakteristik pembelajaran dikelas yang nantinya dapat digunakan untuk membantu pemilihan media pembelajaran yang tepat agar pembelajaran dapat menjadi lebih efektif.

\section{SIMPULAN}

Berdasarkan hasil yang telah didapatkan, peneliti mendapatkan nilai rata-rata sebesar 23,07 yang dimana berada pada rentang kategori dibutuhkan yang menyatakan bahwa e-modul dibutuhkan pada pembelajaran Fisika Matematika khususnya materi vector yang sangat penting bagi mahasiswa. Data tersebut diperkuat dengan hasil wawancara yang mengindikasikan bahwa e-modul perlu dikembangkan dikarenakan sumber yang terdahulu kebanyakan berbahasa inggris. Dengan mengacu pada hasil dan pembahasan, maka dapat disimpulkan bahwa emodul vektor sangat perlu dikembangkan untuk mahasiswa

\section{Ucapan Terima Kasih}

Peneliti mengucapkan terimakasih kepada program studi Pendidikan Fisika Universitas Jambi yang telah mendukung dan memberikan fasilitas kepada peneliti untuk menyelesaikan penelitian, dan kepada mahasiswa/i Pendidikan Fisika angkatan 2019 Universitas Jambi yang telah memberikan kesempatan kepada peneliti untuk melakukan penelitian sehingga terlaksana dengan baik serta pihak-pihak lain yang telah berkontribusi dalam penelitian ini.

\section{Daftar Pustaka}

Ahmad, J., Rahmawati, D., \& Anwar, R. B. (2020). Proses Translasi Representasi Siswa dalam Menyelesaikan Permasalahan Matematika yang Berorientasi pada High Order Thinking Skills. Aksioma: Jurnal Program Studi Pendidikan Matematika Volume, 9(3), 631-640.

Amilia, T. N., Andriani, N., \& Zulherman. (2016). Matematika Pokok Bahasan Bilangan Kompleks Di. Jurnal Inovasi Dan Pembelajaran Fisika, 3(2), 1-7.

Astalini, Darmaji, Kurniawan, D. A., \& Ramadhanti, A. (2021). Students' Perceptions of the E-Module in Mathematics and Physics Based on Gender Differences. Journal of Educational Research and Evaluation, 5(4), 587-597.

Astalini, Darmaji, Kurniawan, W., Anwar, K., \& Kurniawan, D. A. (2019). Effectiveness of Using E-Module and E-Assessment. IJIM, 13(9), 21-39.

Ayu, H. D., Saputra, S., Sarwanto, S., \& Mulyani, S. (2021). Diagnostic analysis of student concept in environmental physics. Journal of Physics: Conference Series, 1869(1), 012177. https://doi.org/10.1088/1742-6596/1869/1/012177

Busetto, L., Wick, W., \& Gumbinger, C. (2020). How to use and assess qualitative research methods. Neurological Research and Practice, 2(1), 1-10. https://doi.org/10.1186/s42466-020-00059-z

Darmaji, Astalini, Kurniawan, D. A., Parasdila, H., \& Iridianti. (2019). E-Module Based Problem Solving in Basic Physics Practicum for Science Process Skills. IJOE, 15(15), 4-17.

Darmaji, D., Kurniawan, D. A., Astalini, A., Kurniawan, W., Anwar, K., \& Lumbantoruan, A. (2019). Students' perceptions of electronic's module in physics practicum. Journal of Education and Learning (EduLearn), 13(2), 288-294. https://doi.org/10.11591/edulearn.v13i2.13005

Ellianawati, \& Wahyuni, S. (2012). Pengembangan Bahan Ajar Fisika Matematika Berbasis Self Regulated Learning Sebagai Upaya Peningkatan Kemampuan Belajar Mandiri. Jurnal Pendidikan Fisika Indonesia, 8(1), 33-40. https://doi.org/10.15294/jpfi.v8i1.1992

Hasyim, N., \& Haling, A. (2017). The e-Learning Needs Analysis in Graduate Programs of Universitas Negeri Makassar. Journal of Educational Science and Technology (EST), 3(3), 233-242.

Huda, S., Firmansyah, M., Rinaldi, A., Sugiharta, I., Astuti, D. W., Fatimah, O., \& Prasetyo, A. E. (2019). Understanding Of Mathematical Concepts In The Linear Equation With Two Variables: Impact Of ELearning And Blended Learning Using Google Classroom. Jurnal Pendidikan Matematika, 10(2), 261-270.

Kimbrel, L. A. (2020). The Impact of a Structured Protocol on Graduate Student Perception of Online Asynchronous Discussions. Journal of Curriculum and Teaching, 9(3), 172-181. 
https://doi.org/10.5430/jct.v9n3p172

Mahande, R. D. (2019). IS Success Model for EDMODO E-learning User Satisfaction through TAM on Students. Journal of Educational Science and Technology (EST), 5(2), 140-152.

Marshman, E., Kalender, Z. Y., Schunn, C., Nokesh-Malach, T., \& Singh, C. (2017). A longitudinal analysis of students' motivational characteristics in introductory physics courses: Gender differences. Canadian Journal of Physics, 1-23.

Mazidah, Erna, M., \& Anwar, L. (2020). Developing an Interactive Chemistry E-Module for Salt Hydrolysis Material to Face the Covid-19 Pandemic Developing an Interactive Chemistry E-Module for Salt Hydrolysis Material to Face the Covid-19 Pandemic. Journal of Physics: Conference Series, 1-6. https://doi.org/10.1088/1742-6596/1655/1/012051

Mulyadi, R, S., Atmazaki, \& Agustina. (2020). The Development Of E-Modules Based on Adobe Flash For Indonesian Subjects At IAIN Bukittinggi The Development Of E-Modules Based on Adobe Flash For Indonesian Subjects At IAIN Bukittinggi. Journal Of Physics Conference Series, 1471, 1-9. https://doi.org/10.1088/1742-6596/1471/1/012002

Nisa, W. L., \& Andriani, N. (2020). Development of E-Modules Based on Multi-representations in Solid-State Physics Introductory Subject. Berkala Ilmiah Fisika, 8(2), 73-81. https://doi.org/10.20527/bipf.v8i2.7690

Nurabadi, A., Sucipto, S., Juharyanto, J., \& Gunawan, I. (2018). The Implementation of Education Management Standards in the School Laboratory State University of Malang for Improving Educational Quality. Education and Humanities Research, 269, 127-132. https://doi.org/10.2991/coema-18.2018.33

Odhier, P. O., Ajowi, J. O., \& Mwebi, B. (2019). Investigation on Contributions of Principals on School Machinery and Equipment Management in Secondary Schools in Kenya. International Journal of Novel Research in Humanity and Social Science, 6(5), 73-88.

Petrova, L. (2020). Discrete Quantum Transitions, Duality: Emergence of Physical Structures and Occurrence of Observed Formations (Hidden Properties of Mathematical Physics Equations). Journal of Applied Mathematics and Physics, 08(09), 1911-1929. https://doi.org/10.4236/jamp.2020.89144

Puspitasari, A. D. (2019). Penerapan Media Pembelajaran Fisika Menggunakan Modul Cetak dan Modul Elektronik pada Siswa SMA. Jurnal Pendidikan Fisika, 7(1), 17-25.

Rahayu, I., \& Sukardi. (2020). The Development Of E-Modules Project Based Learning for Students of Computer and Basic Networks at Vocational. Journal Of Education Technology, 4(4), 398-403.

Rendra, G. R. P., Darmawiguna, I. G. M., \& Sindu, I. G. P. (2018). Pengembangan e-modul berbasis project based learning menggunakan schoology. Karmapati, 7(2), 50-58.

Riantoni, C., Yuliati, L., Mufti, N., \& Nehru, N. (2017). Problem solving approach in electrical energy and power on students as physics teacher candidates. Jurnal Pendidikan IPA Indonesia, 6(1), 55-62. https://doi.org/10.15294/jpii.v6i1.8293

Saputri, D. F., Fadilah, S., \& Wahyudi, W. (2016). Efektivitas Penggunaan Buku Ajar Fisika Matematika Berbasis Inkuiri dalam Perkuliahan Fisika Matematika. Jurnal Penelitian $\mathcal{F}$ Pengembangan Pendidikan Fisika, 02(2), 7-14. https://doi.org/10.21009/1.02202

Sari, U., Hajiomer, A., Güven, K., \& Faruk, Ö. (2017). Effects of the 5E Teaching Model Using Interactive Simulation on Achievement and Attitude in Physics Education. International Journal of Innovation in Science and Mathematics Education, 25(3), 20-35.

Serevina, V., Sunaryo, Raihanati, Astra, I. M., \& Sari, I. J. (2018). Development of E-Module Based on Problem Based Learning ( PBL ) on Heat and Temperature to Improve Student's Science Process Skill. The Turkish Online Journal of Educational Technology, 17(3), 26-36.

Sitorus, D. S., Siswandari, \& Kristiani. (2019). CHARACTER VALUE TO IMPROVE STUDENTS ' LEARNING OUTCOMES AND. Cakrawala Pendidikan, 38(1), 120-129. https://doi.org/10.21831/cp.v38i1.20878

Sutarno, S., Setiawan, A., Kaniawati, I., \& Suhandi, A. (2017). Pre-Service Physics Teachers' Problem-solving Skills in Projectile Motion Concept. Journal of Physics: Conference Series, 895(1). https://doi.org/10.1088/1742-6596/895/1/012105

Trianggono, M. M. (2017). Analisis Kausalitas Pemahaman Konsep Dengan Kemampuan Berpikir Kreatif Siswa Pada Pemecahan Masalah Fisika. Jurnal Pendidikan Fisika Dan Keilmuan (JPFK), 3(1), 1. https://doi.org/10.25273/jpfk.v3i1.874

Vebrianto, R., \& Syafaren, A. (2018). BIOMIND Module : A Quality Teaching and Assessment Media. Journal 
of Educational Science and Technology (EST), 4(1), 62-73.

Wartono, W., Hudha, M. N., \& Batlolona, J. R. (2018). How are the physics critical thinking skills of the students taught by using inquiry-discovery through empirical and theorethical overview? Eurasia Journal of Mathematics, Science and Technology Education, 14(2), 691-697. https://doi.org/10.12973/ejmste/80632 